\title{
JORNADA DE TRABALHO NA PMRN: O ESTABELECIMENTO DE LIMITE E VIABILIDADE DE IMPLANTAÇÃO DE BANCO DE HORAS NAS UNIDADES OPERACIONAIS DO COMANDO DE POLICIAMENTO METROPOLITANO
}

\author{
GUSTAVO HENRIQUE LINS BARRETO
}

Capitão da PMRN, Bacharel em Segurança Pública pela Academia de Policia Militar do RN e Pós-Graduado em Gestão de Pessoas pela Universidade Estadual do Rio Grande do Norte. Autor dos Manuais Técnicos "Operações de Choque" e "Munições de Menor Potencial Ofensivo" ambos da PMRN. Instrutor nos cursos da corporação e nas có-irmãs, além da Força Nacional de Segurança Pública. Tem experiência nas áreas de Operações de Choque, Policiamento em Eventos, Uso diferenciado da força, e Instrumentos de Menor Potencial Ofensivo.

\section{RESUMO}

O presente estudo foi realizado com o objetivo de analisar as horas de trabalho na Polícia Militar do Rio Grande do Norte para as atividades de policiamento e administrativas, em comparação com o aplicado ao trabalhador comum, explorando a aplicação dos fundamentos do banco de horas nas unidades do Comando de Policiamento Metropolitano, com o propósito de propor as condições de execução através dos resultados aplicados. Para realizar o estudo foi aplicada a metodologia da pesquisa bibliográfica e documental, e pesquisa-ação, com a aplicação de questionário com policiais militares do estado. Os resultados permitiram verificar que o banco de horas tem o potencial de representar uma solução viável para o controle das atividades profissionais dos policiais militares, assegurando maior eficiência na segurança pública estadual. A conclusão apresenta os resultados obtidos e propõe a utilidade do banco de horas no policiamento ostensivo e no serviço administrativo, como forma de garantir a eficiência no uso racional dos recursos humanos.

Palavras chave: Polícia Militar. Banco de horas. Jornada de trabalho. Segurança Pública.

\section{ABSTRACT \\ WORKING JOURNEY AT MPRN: THE ESTABLISHMENT OF LIMIT AND FEASIBILITY OF IMPLEMENTING HOUR BANK IN THE OPERATIONAL UNITS OF THE METROPOLITAN POLICE COMMAND}

The present study was carried out with the objective of analyzing the working hours in the Military Police of Rio Grande do Norte for policing and administrative activities, comparing with the one applied to the common worker to explore the application of the foundations of the hour bank in the units of the Metropolitan Police Command, as the purpose of proposing the conditions of execution through the applied results. In order to carry out the study, the methodology of bibliographic and documentary research and action research was applied, with the application of a questionnaire with a sample of the state police force. The results allowed to verify that the hour bank has the potential to represent a viable solution for the control of the professional activities of the military police, ensuring that greater efficiency in the state public security is achieved. The 
conclusion presents the results obtained and proposes the usefulness of the time bank in ostensive policing and in the administrative service, as a way of guaranteeing efficiency in the rational use of human resources. Key words: Military police. Hours Bank. Working day. Public security.

DOI: 10.31060/rbsp.2020.v14.n2.894

Data de recebimento: 08/01/2018 - Data de aprovação: 21/09/2018

\title{
1. INTRODUÇÃO
}

A Policia Militar do Rio Grande do Norte (PMRN) não tem conseguido manter uma padronização no que tange às horas trabalhadas nos seus setores, ainda que exista uma norma interna que regule os horários de seus diversos órgãos, ficando a critério de cada comandante de organização policial militar (OPM) gerenciar seu efetivo, o que gera desconforto entre aqueles que exercem atividade-fim (policiamento em suas diversas modalidades) e atividade-meio (administrativo).

Não tem sido possível, também, padronizar as horas trabalhadas entre unidades que exerçam a atividadefim, possuindo horários diferenciados, (tudo com respaldo de seus comandantes na questão de benefícios de horários), gerando com isso ineficiência institucional, em que muitas vezes se necessita o dobro de pessoal para exercer a mesma atividade.

Dessa forma, o presente trabalho teve como objetivo geral analisar as horas de trabalho na Polícia Militar do Rio Grande do Norte para as atividades de policiamento e administrativas, comparando-as com o aplicado ao trabalhador comum. Como consequência dessa análise ampla, o foco parte para a identificação da viabilidade e interesse na implantação do banco de horas, no Comando de Policiamento Metropolitano da Policia Militar do Rio Grande do Norte e nas Unidades Administrativas, por parte dos seus gestores e executores; realizar diagnóstico acerca das horas trabalhadas nos setores administrativos e operacionais dentro das Organizações Policiais Militares do Comando de Policiamento Metropolitano sediadas em Natal- (RN); por fim, identificar se há aceitação de que as atividades tenham limite de 44 horas semanais, conforme é aplicado ao trabalhador comum.

\section{REVISÃO TEÓRICA}

\subsection{A JORNADA DE TRABALHO PARA O TRABALHADOR COMUM EM COMPARAÇÃO COM A DO POLICIAL MILITAR}

A Constituição do Estado do Rio Grande do Norte, em seu $\$ 1^{\circ}$ do Art. 31, diz que:

\author{
Art. 31. \\ $[\ldots]$ \\ $\S 1^{\circ}$. Aplicam-se aos militares do Estado, além do que vier a ser fixado em lei, as disposições \\ do art. 14 , § $8^{\circ}$; do art. 40 , $\S 9^{\circ}$; e do art. 142 , $\S \S 2^{\circ}$ e $3^{\circ}$, todos da $C F$, cabendo à lei estadual \\ dispor sobre as matérias do art. $142, \S 3^{\circ}$, inciso X, sendo as patentes dos oficiais conferidas pelo \\ Governador do Estado (RIO GRANDE DO NORTE, 1989, grifo nosso).
}

Observa-se então que, dentre outros dispositivos, aplica-se aos militares estaduais o prescrito no parágrafo $3^{\circ}$ do Art. 142, da Constituição Federal (CF), conforme disposto em ambas as constituições. 
Ao verificar o parágrafo $3^{\circ}$ do Art. $142^{\circ}$ da CF, consta que "aplica-se aos militares o disposto no art. $7^{\circ}$, incisos VIII, XII, XVII, XVIII, XIX e XXV [...]" (BRASIL, 1988).

É importante reparar, então, que o Art. $7^{\circ}$ da CF trata dos direitos dos trabalhadores urbanos e rurais, e em especial podemos destacar o seu inciso XIII, que trata acerca da jornada de trabalho:

Art. $7^{\circ}$ São direitos dos trabalhadores urbanos e rurais, além de outros que visem à melhoria de sua condição social:

$[\ldots]$

XIII - duração do trabalho normal não superior a oito horas diárias e quarenta e quatro semanais, facultada a compensação de horários e a redução da jornada, mediante acordo ou convenção coletiva de trabalho. (BRASIL, 1988, grifo nosso).

Conforme citado anteriormente, pode-se observar que o dispositivo que trata das horas trabalhadas não foi contemplado pelo art. 142 da CF, ou seja, não está inserido como direito dos policiais militares, analogamente à limitação da jornada de trabalho.

Assim, se observa que os Militares Estaduais possuem características próprias que diferem dos demais servidores públicos, pois, pela sua natureza especial, uma série de deveres e normas lhes são atribuídas, podendo em casos excepcionais trabalhar ininterruptamente, se a situação assim exigir.

Como qualquer trabalhador, os Policiais Militares exercem suas funções dentro de um espaço de tempo, ou jornada de trabalho, no qual existe uma contraprestação do Estado para com o servidor.

\subsection{AS DIFERENTES ATIVIDADES DESEMPENHADAS NA PMRN E A BUSCA DE MELHORIA NA GESTÃO PÚBLICA}

Dentro da Polícia Militar do Rio Grande do Norte existem diversos serviços a serem realizados, desde a sua missão constitucional de policiamento ostensivo até aquelas que servem de apoio a sua execução.

Realizando uma rápida análise dessas diversas atividades desempenhadas pelos policiais militares, é possível perceber que existe uma diferença notória acerca das horas trabalhadas, principalmente entre as atividades operacionais e atividades administrativas.

Com essa diferença percebem-se alguns aspectos que influenciam diretamente no desempenho de algumas atividades, além de influenciar proporcionalmente na motivação daqueles que estão exercendo a atividade-fim.

Matas (2005) assevera que:

Neste sentido, a Nova Gestão Pública está orientada no sentido de incrementar a eficácia e eficiência da administração pública. Esta busca é lógica e transcendente devido ao fato de que a ausência de eficácia e eficiência no setor público põe em risco sua legitimidade e estabilidade (MATAS, 2005, p.184). 
O setor privado procura constantemente a máxima eficiência e essa busca por eficiência deve servir de exemplo para o setor público, que não pode negar que as inovações do universo empresarial, pela própria necessidade de competição que lhes são impostos, são fundamentais para a melhoria e otimização dos seus processos.

Dessa forma, parece razoável para as organizações públicas que as boas práticas realizadas no setor privado possam ser aproveitadas (e adaptadas as suas peculiaridades), com o objetivo de melhoria do serviço oferecido a população, diferentemente do setor privado, que busca rentabilidade sem necessariamente servir ao público.

\subsection{DAS NORMAS REGULAMENTADORAS DAS JORNADAS DE TRABALHO}

O Art. $4^{\circ}$ do Decreto-Lei 5.452 de 1943, a Consolidação das Leis do Trabalho (CLT), define jornada de trabalho "como de serviço efetivo o período em que o empregado esteja à disposição do empregador, aguardando ou executando ordens, salvo disposição especial expressamente consignada" (BRASIL, 1943).

Como instituição militar, e já observado anteriormente, os integrantes da PMRN não são regidos pela CLT, assim como nem todos os dispositivos constantes no Art. $7^{\circ} \mathrm{da}$ CF lhes foram concedidos, sendo regidos dessa forma por estatutos internos, mais especificamente pela Lei 4.630/1976 (Estatuto dos Policiais Militares do Estado do Rio Grande do Norte), na qual estão contidos os direitos, deveres, bem como suas recompensas e benefícios. Porém, nesse mesmo dispositivo legal, não consta menção quanto à quantidade de horas trabalhadas.

De acordo com o Art. 141 do Estatuto dos Policiais Militares do Estado do Rio Grande do Norte, "são adotados na Polícia Militar, em matéria não regulada na legislação estadual, as leis e regulamentos em vigor no Exército Brasileiro, no que lhe for pertinente" (RIO GRANDE DO NORTE, 1976).

Remetendo ao Regulamento Interno e dos Serviços Gerais do Exército (RISG), encontramos o Art. 185, que define que serviço de escala é "todo o serviço não atribuído permanentemente à mesma pessoa, ou fração de tropa, e que não importe em delegação pessoal ou escolha” (BRASIL, 2003).

Ainda conforme o RISG, a definição do período de duração das escalas está contida no parágrafo terceiro do Art. 189:

Art. 189. O serviço interno abrange todos os trabalhos necessários ao funcionamento da unidade e compreende o serviço permanente e o serviço de escala.

$[\ldots]$

$\S 3^{\circ} \mathrm{O}$ serviço de escala tem a duração de vinte e quatro horas, de Parada a Parada, salvo o de faxina que será contado por jornada completa, do início até o término do expediente (BRASIL, 2003, grifo nosso).

Voltando ao art.185 do mesmo regulamento, observa-se no inciso V, no que se refere à folga: "entre dois serviços de mesma natureza ou de natureza diferente, observar-se-á, para o mesmo indivíduo, no mínimo a folga de quarenta e oito horas, sempre que possível" (BRASIL, 2003, grifo nosso). 
Dessa forma, observa -se que, de acordo com o art. 185, deve buscar intervalo mínimo de 48 horas entre os serviços de 24 horas. No entanto, a expressão "sempre que possível" permite que, em situações extraordinárias, deva haver pessoal disponível para cumprir tarefas, caso isso seja considerado necessário pelo Comandante, ao mesmo tempo que não se estabelece um limite para a jornada de trabalho.

\subsection{REGULAMENTAÇÃO DA JORNADA DE TRABALHO NA PMRN}

No ano de 2009, tem-se a primeira normatização da jornada de trabalho para os policiais militares do Rio Grande do Norte, através da Portaria nº. 204/09-GCG de 08 de setembro de 2009, conforme publicado no Boletim Geral No 167 de 08 de setembro de 2009:

\section{O COMANDANTE GERAL DA POLÍCIA MILITAR DO RIO GRANDE DO NORTE [...], RESOLVE:}

Determinar aos Comandantes de OPMs Operacionais que as escalas de serviços das guarnições rádio motorizadas, quando executadas:

1. Nos horários matutinos e vespertinos, serão de 12 horas de trabalho, por 24 horas de folga.

2. Nos horários noturnos, serão de 12 horas de trabalho por 48 horas de folga (POLíCIA MILITAR DO RIO GRANDE DO NORTE, 2009).

Tal medida assegurou a jornada semanal de trabalho de 48 horas, porém foi omissa no constante a outras modalidades de policiamento e tipos de serviço, como policiamento em guarita de presídios e as atividades-meio.

Em 13 de abril de 2010, foi editada a Resolução Administrativa nº 002/2010 - GCG, que instituía a jornada de trabalho no âmbito da Polícia Militar e dava outras providências, resolução esta publicada no Boletim Geral №. 066, de 13 de abril de 2010:

O COMANDANTE GERAL DA POLÍCIA MILITAR DO ESTADO DO RIO GRANDE DO NORTE no uso das atribuições que lhe confere o artigo 4², da Lei Complementar Estadual $n^{\circ}$. 090, de 04 de janeiro de 1991 ecombinado comos artigos nº.184e 185 do Regulamentolnterno de Serviços Gerais-RISGe [...] RESOLVE:

Art. $1^{\circ}$ - Fica estabelecida no âmbito da Polícia Militar, a Jornada de Trabalho no serviço operacional motorizado nos turnos matutino e vespertino de 12 horas de serviço, por 24 horas de folga e no turno noturno de 12 horas de serviço por 48 horas de folga.

Art. $2^{\circ}$ - As Escalas de Serviço de guardas de quartéis presídios e estabelecimentos prisionais congêneres serão na jornada de 24 horas de serviço com 48 noras de folga, obedecendo a rotatividade nos quartos de horas, com duas horas de serviço e quatro horas de descanso.

Art. $3^{\circ}$ - As Jornadas de Trabalho nas Unidades Operacionais Especializadas serão ajustadas de acordo com a modalidade de policiamento e necessidade do serviço, sempre que possível compensada com período de folga. (POLÍCIA MILITAR DO RIO GRANDE DO NORTE, 2010, grifo nosso). 
Dessa forma, foi corrigida a omissão, quanto às guardas de presídios e quartéis, bem como às modalidades de policiamentos diferentes do motorizado, porém ainda não se definia a jornada de trabalho para aqueles que realizavam atividades administrativas.

Importante ressaltar que todas essas normativas não eram cumpridas rigorosamente, sendo que cada Comandante de OPM fazia o horário do serviço conforme seu próprio critério, fato que gerava grandes discrepâncias no serviço ostensivo motorizado.

Assim, pode-se afirmar que a norma existia de fato, mas não era executada, pois por conveniência era adotada a escala que melhor conviesse ao Comandante de cada OPM.

Conforme mencionado anteriormente, deve-se trabalhar 44 horas semanais ou 176 horas mensais. Dessa forma, observa-se que, para adequar o serviço de policiamento ostensivo, que atualmente é de 24 horas de serviço contínuo, com 72 horas de descanso, o policial militar trabalha 16 horas a mais.

Vale salientar que, até o presente momento, foi tratado apenas o serviço ostensivo, sendo omitido o tratamento da atividade-meio.

Finalmente, foi publicada no Boletim Geral № 154, de 15 de agosto de 2013, a Resolução Administrativa No 011/2013, que estabelecia o horário do expediente administrativo na Polícia Militar do Rio Grande do Norte e dava outras providências:

Art. $1^{\circ}$ - Estabelecer que o expediente administrativo na PMRN será das 07 às 14 horas.

$[\ldots]$

Art. $2^{\circ}$ - O disposto no artigo anterior não se aplica ao Gabinete do Comandante Geral e Subcomandante Geral e Chefe do Estado-Maior Geral.

$[\ldots]$

$\S 1^{\circ} \mathrm{A}$ jornada de trabalho do militar ou servidor que cumpre expediente administrativo é de 7 (sete) horas com intervalo facultativo, a critério de cada Comandante imediato;

$\S 2^{\circ}$ Os servidores de outros órgãos que estejam à disposição da Polícia Militar sujeitar-se-ão à jornada de trabalho a que se refere o parágrafo anterior, independentemente da carga horária adotada no órgão de origem.

$\S 3^{\circ} \mathrm{O}$ militar ou servidor que cumprir jornada de 7 (sete) horas poderá usufruir intervalo com duração inferior a 1 (uma) hora, mediante comunicado ao seu Comandante imediato ou substituto legal, antes e depois. A partir de 1 (uma) hora de intervalo, o servidor cumprirá jornada de 8 (oito) horas neste dia.

$[\ldots]$

Art. $7^{\circ}$ - A presente Resolução entrará em vigor, na data de sua publicação, sendo válida até 31 de dezembro de 2013, conforme previsão contida no $\S 1^{\circ}$, do artigo 26, da Lei Complementar № 303, de 09 de setembro de 2005, salvo ulterior deliberação.

Art. $8^{\circ}$ - Ficam revogadas as demais disposições em contrário (POLÍCIA MILITAR DO RIO GRANDE DO NORTE), 2013).

Essa resolução preencheu uma lacuna e estabeleceu jornada semanal de 35 horas semanais para todos que exerciam atividades administrativas, mantendo a diferença entre os serviços operacionais e administrativos, com uma diferença de 16 horas a menos para as atividades administrativas, 
comparadas com aquelas do serviço operacional, porém sua eficácia foi revogada conforme já previsto na norma.

Em 22 de setembro de 2015, no Boletim Geral No 176, foi baixada a Portaria No 107/2015-GCG, de 22 de setembro de 2015, que revogou a resolução administrativa 001/2013:

Art. $1^{\circ}$ - Fica estabelecida no âmbito da Polícia Militar, a Jornada de Trabalho no serviço operacional motorizado nos turnos matutino e vespertino de 12 horas de serviço, por 24 horas de folga e no turno noturno de 12 horas de serviço por 48 horas de folga.

Art. $2^{\circ}$ - As Escalas de Serviço de Guardas de quartéis, Presídios e Estabelecimentos Prisionais congêneres serão na jornada de 24 horas de serviço com 72 horas de folga, obedecendo à rotatividade nos quartos de horas, com duas horas de serviço e quatro horas de descanso.

Art. $3^{\circ}$ - As Jornadas de Trabalho nas Unidades Operacionais Especializadas serão ajustadas de acordo com a modalidade de policiamento e necessidade do serviço, sempre que possível compensadas com período de folga.

$[\ldots]$

Art. $6^{\circ}$ - Esta Portaria entra em vigor na data de sua publicação, revogando-se o contido na Resolução Administrativa nº 001/2013 - GCG, publicada no BG Nº. 061 de 03 de abril de 2013. (POLÍCIA MILITAR DO RIO GRANDE DO NORTE, 2015, grifo nosso).

Essa portaria mudou o período de descanso para serviços de Guardas de quartéis, Presídios e Estabelecimentos Prisionais congêneres de 48 para 72 horas, mantendo a escala de 12 horas trabalhadas por 24 horas de descanso e, em seguida, 12 horas trabalhadas por 48 de descanso.

Por fim, no Boletim Geral № 187, de 07 de outubro de 2015, foi publicada a Portaria № 113/2015-GCG, que alterou o Artigo $2^{\circ}$, da Portaria No 107/2015-GCG, no qual fez-se uma correção no tocante às escalas de guardas: "[...] As Escalas de Serviço de Guardas de quartéis, Presídios e Estabelecimentos Prisionais congêneres serão na jornada de 24 horas de serviço com 72 horas de folga [...]" (POLíCIA MILITAR DO RIO GRANDE DO NORTE, 2015, p. 22), tendo-se aumentado de 48 para 72 horas o descanso entre os serviços.

Entre a Portaria $n^{\circ}$. 204/09-GCG, de 08 de setembro de 2009 (primeira norma que estabeleceu a jornada de trabalho na PMRN), e a Portaria No 113/2015-GCG, de 7 de outubro 2015, foi iniciado o seu cumprimento dessa jornada, mas ele deixou de ser executado, por motivos diversos que não são objeto do presente trabalho.

\subsection{O SERVIÇO ADMINISTRATIVO NA PMRN E O PRINCÍPIO DA EFICIÊNCIA}

No desempenho das atividades-meio, é comum que o período de trabalho seja de meia jornada, ficando novamente a cargo de cada comandante definir a hora e período, mesmo com o advento da resolução citada.

Há de se considerar que existe a necessidade do funcionamento dos serviços administrativos em jornadas matutinas e vespertinas, porém observa-se que, para a realização da mesma atividade, são necessárias duas pessoas, uma em cada jornada, para a continuidade do trabalho. 
A grosso modo, neste caso, percebe-se que o custo para execução da tarefa dobra, pois são necessárias duas pessoas exercendo de maneira alternada uma demanda que facilmente um policial militar poderia exercer.

Assim, tratando-se de administração pública, a CF trata em seu Art. 37:

Art. 37 A administração pública direta e indireta de qualquer dos Poderes da União, dos Estados, do Distrito Federal e dos Municípios obedecerá aos princípios de legalidade, impessoalidade, moralidade, publicidade e eficiência [...] (BRASIL, 1988, grifo nosso).

Dessa forma, utilizar dois servidores, onde bastaria um ajuste de horas trabalhadas, teria mesma eficiência, porém com custos reduzidos e, consequentemente, melhor aproveitamento dos recursos humanos disponíveis.

Acerca do princípio da eficiência, Meireles, afirma que:

O que se impõe a todo o agente público de realizar suas atribuições com presteza, perfeição e rendimento profissional. É o mais moderno princípio da função administrativa, que já não se contenta em ser desempenhada apenas com legalidade, exigindo resultados positivos para o serviço público e satisfatório atendimento das necessidades da comunidade e de seus membros", e acrescenta que "o dever da eficiência corresponde ao dever da boa administração (MEIRELES, 2002, apud VIANA, 2012).

Miranda, ao justificar a inclusão do princípio da eficiência na CF, afirma que isso significa "[...] permitir que a Administração ofereça ao cidadão mais serviços, com melhor qualidade, em menor preço" (MIRANDA, 2005 apud VIANA, 2012, p.97).

Após a perda da validade da Resolução Administrativa No 011/2013, deixou de existir norma regulamentadora para as atividades administrativas, carecendo-se então de nova norma e, outra vez, deixando a critério de cada Comandante, Chefe ou Diretor a sua regulação. Mas a regra ainda vigente na maioria das atividades meio é de meio expediente, durante os cinco dias úteis ou um expediente completo por outro dia completo de descanso.

Considerando-se que o policial militar trabalhe todos os dias úteis na semana, das 7 às 12 horas, perfazse um total de 25 horas trabalhadas na semana e, considerando o mês de 22 dias úteis dias, 110 horas trabalhadas no mês. Sem entrar no mérito sobre qual atividade é a mais importante (atividade-fim ou meio), nem sobre qual é mais desgastante ou exige mais do policial militar, percebe-se que existe uma diferença de 82 horas trabalhadas a menos, comparado com quem executa uma jornada de 24 horas de serviço por 72 horas de descanso.

\subsection{DO BANCO DE HORAS}

Banco de horas é a denominação do que se atribui à flexibilização da jornada de trabalho, mediante uma relação entre números de horas trabalhados e o estabelecido em contrato de quanto o trabalhador deve executar.

Machado (apud Campos e Pires, 2014, p. 4) afirma que a flexibilização do trabalho é entendida "como a forma que os agentes econômicos, trabalhadores e empregados, buscam se adequar ao novo contexto resultante de fenômenos de natureza conjuntural e estrutural". 
Machado assevera ainda que:

A flexibilidade do tempo de trabalho pode ser compreendida a partir de dois aspectos: número de horas de trabalho (jornada de trabalho diária, semanal, mensal ou anual, dependendo do período de referência) e montante de dias trabalhados (jornada por dias trabalhados ao longo da vida, contando férias, aposentadoria, etc.) (MACHADO, 2012, p.13).

Dessa forma, a partir da Lei nº 9.601 de 1998, que trata de contratações temporárias pelo setor privado, foi facultada a adoção do que chamamos de "Banco de Horas", modificado no ano de 2001, através da Medida Provisória No 2.164-4, em seu Art. 2:

Poderá ser dispensado o acréscimo de salário se, por força de acordo ou convenção coletiva de trabalho, o excesso de horas em um dia for compensado pela correspondente diminuição em outro dia, de maneira que não exceda, no período máximo de um ano, à soma das jornadas semanais de trabalho previstas, nem seja ultrapassado o limite máximo de dez horas diárias (BRASIL, 2001).

Conforme Pantaleão, o banco de horas surgiu no Brasil no "[...] momento em que o país atravessava uma grande recessão econômica que gerou a demissão de centenas de trabalhadores, além do encerramento de atividades de muitas empresas." (PANTALEÃO, 2012). A ideia por trás da modificação da referida lei seria conceder folgas durante alguma crise que a empresa viesse a sofrer, em troca da manutenção do emprego.

Para Pina e Stoltz, "a jornada de trabalho diária pode ser ampliada ou reduzida e as horas trabalhadas a mais ou a menos são contabilizadas como positivas ou negativas no banco de horas" (PINA; STOTZ, 2011, p.169).

Dessa forma, рага gerar equidade entre as horas trabalhadas e visando a eficiência do serviço público, normas internas da corporação poderiam ser implementadas, e, ao final de um intervalo de tempo, o policial militar teria um saldo positivo, negativo ou neutro, podendo-se dessa forma equiparar as quantidades de horas trabalhadas por todos.

Blass, em seu trabalho acerca da jornada de trabalho na região do ABC paulista, assevera que:

As folgas individuais ou coletivas, como as "pontes de feriado", podem ser usufruídas a qualquer momento, desde que consentidas pelos supervisores imediatos. Por exemplo, os dias entre o Natal e o Ano Novo, que totalizaram nove dias em 1996: quatro deles foram debitados do banco de horas (Tribuna Metalúrgica, 6/11/1996). Os atrasos, saídas antecipadas e as faltas injustificadas são debitados do banco de horas, e não descontados do descanso semanal remunerado ou das férias. O valor proporcional das horas excedentes está automaticamente incorporado aos salários mensais desde janeiro de 1996. Cada funcionário recebe, mensalmente, um holerite especial onde são registrados o total de horas trabalhadas, os adicionais e o saldo no banco de horas (BLASS, 1998, p. 7).

Aliando a sua demanda pessoal, o policial militar utilizaria as suas horas de "crédito", para se programar ou até mesmo, em caso de alguma demanda inesperada, contar com essas horas que the sobram.

Fazendo a mesma analogia, porém de maneira inversa, um policial militar que não atinja as horas demandadas, cumpriria o restante das suas horas em escalas de reforço de policiamento, nas mais variadas 
operações a serem empregadas, sem custar ao erário estadual o valor de uma Diária Operacional (DO), pois ainda estaria dentro do limite das suas horas a serem cumpridas.

Robbin afirma que:

Estudos sugerem que os trabalhadores desejam empregos com mais flexibilidade de horários para que possam compatibilizar melhor os assuntos pessoais aos profissionais. Temas como equilíbrio entre vida pessoal e trabalho são cada vez mais constantes nos processos de seleção e retenção de recursos humanos. [...] As organizações que não conseguirem ajudar seu pessoal a atingir esse equilíbrio vão encontrar dificuldades crescentes para atrair e reter os funcionários mais capazes e motivados (ROBBIN, 2005, apud SILVA, 2012, p. 25).

Não resta dúvida que os interesses particulares dos policiais militares devem ser concedidos na medida, e dentro do limite possível, além de ser obrigação dos comandantes em todos os níveis, a manutenção do bem-estar dos seus subordinados.

\section{MATERIAL E MÉTODOS}

Em relação aos métodos adotados neste artigo, utilizou-se a pesquisa documental e a pesquisa bibliográfica. A pesquisa documental, feita a partir do levantamento de documentos das esferas federal e estadual referentes à flexibilização da jornada de trabalho, e das normas internas vigentes na corporação militar.

Foi realizada pesquisa bibliográfica a respeito do tema "flexibilização da jornada de trabalho", primeiramente na legislação federal e estadual e em normas internas vigentes na corporação; em seguida foi pesquisada a aplicação da flexibilização da jornada de trabalho nas empresas privadas.

Finalizada a pesquisa bibliográfica, foi realizada uma pesquisa-ação, pois buscou-se discutir e propor modificação do atual sistema de cargas horárias da PMRN, sendo aplicado um questionário semiestruturado, contendo perguntas abertas e fechadas aos policiais militares, no segundo semestre do ano de 2015, e assim baseado nessas respostas, nortear as possíveis buscas pela mudança.

Foram abordadas, nas perguntas abertas, opiniões livres e pessoais dos entrevistados acerca do tema, para entendermos o ponto de vista do Policial Militar, quanto ao tema proposto; foram aplicados dois tipos de questionários, sendo um para oficiais e outro para praças, devido à especificidade da função desempenhada.

A quantidade de pesquisados na área administrativa foi menor do que a operacional, devido a maior parte dos policiais serem empregados na atividade-fim. Não foi levado em consideração se o Oficial exercia função administrativa ou operacional pois, todos os oficiais, mesmo os que estejam na atividade-fim, exercem de algum modo as atividades-meio.

A realização do questionário foi devidamente autorizada pelo Comandante do Policiamento Metropolitano e durante a aplicação, foi facultada a não identificação, permitindo, em princípio, gerar dados mais confiáveis.

Como já foi dito, questões relativas à opinião sobre o tema da flexibilização e limitação da jornada de trabalho (aplicado tanto para oficiais quanto praças) e cumprimento de jornada de trabalho por turno 
para o serviço operacional (aplicado para praças) foram deixadas em aberto, para livre manifestação da opinião.

\subsection{UNIVERSO E DELIMITAÇÃO DA AMOSTRA}

O Comando de Policiamento Metropolitano da Polícia Militar, conforme decreto $n^{\circ}$ 21.614, de 07 de abril de 2010, é composto por treze OPM, e responsável pela manutenção da ordem pública na região metropolitana de Natal (RIO GRANDE DO NORTE, 2010).

Seis dessas organizações são unidades que possuem responsabilidade territorial de policiamento (10 $\left.\mathrm{BPM}, 3^{\circ} \mathrm{BPM}, 4^{\circ} \mathrm{BPM}, 5^{\circ} \mathrm{BPM}, 9^{\circ} \mathrm{BPM}, 11^{\circ} \mathrm{BPM}\right)$, sendo a pesquisa feita em quatro delas (1० $\mathrm{BPM}, 4^{\circ}$ $\mathrm{BPM} 5^{\circ} \mathrm{BPM}$ e $\left.9^{\circ} \mathrm{BPM}\right)$, todas sediadas na cidade de Natal, perfazendo um total de 64 praças e 18 oficiais.

As demais são unidades com características especiais, pois suas atividades não compreendem uma parte do território, mas sim um tipo especifico de policiamento ${ }^{1}$, como por exemplo a Companhia Independente de Proteção Ambiental, que tem suas atividades voltadas ao policiamento e fiscalização de Zonas de Proteção Ambiental e, dessa forma, suas escalas de trabalho variam conforme necessidade do serviço.

Assim, o foco da pesquisa realizada foi nas OPM com responsabilidade territorial (que realizam o serviço ordinário de polícia militar), que concentra a maior quantidade de efetivo e retrata com maior fidelidade a principal atividade da polícia militar.

É importante saber dos oficiais a respeito do tema, pois conforme visto, mesmo que a norma seja imposta, se não houver aceitação para a sua mudança, a resistência a qualquer alteração no formato atual poderá não alcançar a sua eficiência.

Também foi analisada a função exercida; se exerce função estratégica no comando ou assessoria estratégica de uma OPM (Comandante ou Subcomandante, Estado Maior); se está exercendo função tática (comandante de Companhia) ou se está exercendo função operacional (Comando de Pelotão).

Em cada nível exercido, a influência e percepção podem ser distintas, devido ao maior ou menor contato com o alto comando, ou com os elementos de execução da atividade-fim da polícia militar.

Um comandante de Pelotão, por exemplo, está em maior contato com a rotina e as atividades realizadas pelos policiais militares que estão exercendo função de execução. Dessa forma, poderá ter uma perspectiva diferente do Comandante da OPM, que está mais próximo ao comando da instituição, aos objetivos institucionais e demandas da Secretaria de Segurança Pública.

Dessa forma, do universo de pesquisa dos Oficiais (18), 50\% eram oficiais subalternos, 39\%, oficiais intermediários e $11 \%$ oficiais superiores. Quanto à função, $11 \%$ exerciam o Comando de OPM, $6 \%$ Subcomando de OPM, 44\% Comando de Companhia (Cia) e 39\% Comando de Pelotão (Pel), totalizando 18 PM.

1 A exemplo, Policiamento Ambiental, Policiamento Montado, Policiamento de Choque etc. 
Já para os praças, a importância de sua participação, se dá no caso em que não haja concordância a respeito da limitação da jornada de trabalho, estratégias devem ser adotadas para mostrar a importância da mudança proposta, pois a possibilidade de diminuição na motivação do policial se torna maior, o que aumentaria os casos de absenteísmo no trabalho, ou baixo rendimento na sua atuação.

Foi analisado também o tipo de atividade desempenhada pelos praças, pois cada atividade reflete diretamente a quantidade de horas trabalhadas. A tendência seria: quem trabalha menos horas teria que compensar essa lacuna, e quem trabalha mais horas sentirá um decréscimo em sua jornada.

Assim, do total de sujeitos da pesquisa, 24\% eram Subtenentes (ST) ou Sargentos (Sgt), 17\% de Cabos (Cb) e 59\% de Soldados (Sd) e, desse total, 77\% (49 PM) exerciam função operacional e 23\% (15 PM) função administrativa.

\section{ANÁLISE DA PESQUISA}

\subsection{CARGA HORÁRIA}

Uma das principais perguntas da pesquisa, ligadas ao objetivo geral deste trabalho, visa analisar as horas trabalhadas pelos policiais militares, especialmente os praças, que compõem a maioria do efetivo da Polícia Militar, em seus diversos setores, desde administrativos a operacionais.

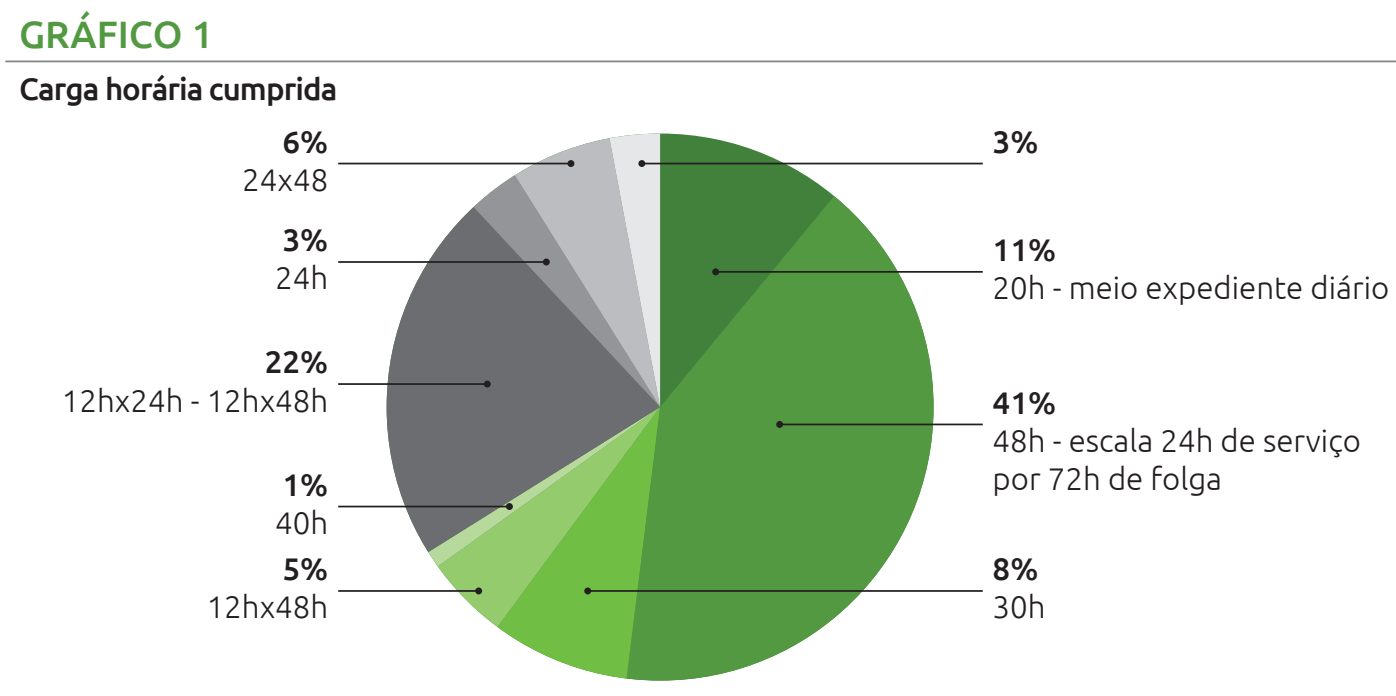

Fonte: Elaboração própria

Observou-se que, ainda que as normas que regulam as jornadas estivessem em vigor desde 2009, com suas evoluções, esta tem uma grande diversidade, refletindo o não cumprimento da determinação emanada pela autoridade maior na Polícia Militar, no caso, o Comandante Geral, como se fosse uma norma a ser facultada pelos comandantes de OPM, o que não é o caso, pois a norma é impositiva.

Em seguida, foi observada a preferência por essa escala de 24 horas de serviço contínuo por $72 \mathrm{~h}$ de folga. Isso se deve ao fato de o policial militar ir menos vezes ao quartel e ter maior descanso corrido. Não pesa nessa preferência a qualidade do serviço prestado. 
Em seguida observou-se que 20\% dos entrevistados exercem, no máximo, 30 horas semanais de trabalho, aproximando-se do percentual de entrevistados que exercem serviço administrativo (23\%).

Dentre os que trabalham no máximo 30 horas por semana, mais da metade trabalha 20 horas, bem menos do que as 48 horas exercidas por aqueles que realizam atividade de policiamento ostensivo, o que mostra a disparidade entre as jornadas de trabalhos executadas pelos policiais militares.

\subsection{EQUIDADE ENTRE OS DIVERSOS TIPOS DE ATIVIDADES OPERACIONAIS LIMITANDO A CARGA HORÁRIA EM 44 HORAS SEMANAIS}

A maioria dos oficiais acredita que a implantação do banco de horas poderia trazer equidade, caso se limitasse a jornada semanal a 44 horas (72\%). Porém no círculo dos praças, as opiniões são dividas (53\% acreditam que traria equidade).

\subsection{CONHECIMENTO DA EXISTÊNCIA DA ATUAL JORNADA DE TRABALHO DA PMRN}

Sobre às atuais normas em vigor, (por turno, 12h/24h, 12h/48h), mais da metade (60\%) dos praças desconhece que existe a norma regulamentadora da corporação, instituída desde 2009. Quase idêntico aos praças, o conhecimento de tal norma pelos oficiais também alcançou menos da metade (39\% conheciam a norma).

Isso reflete que, mesmo com mecanismos de divulgação das normas existentes, (o Boletim Geral da PMRN é disponibilizado, diariamente, na intranet), a comunicação interna carece de melhor divulgação e explanação de ordens, com o objetivo de ter alcance para toda a corporação.

\subsection{ACEITAÇÃO DA IMPLANTAÇÃO DE JORNADA DE TRABALHO POR TURNO}

Conforme resultado, a maioria dos oficiais e praças são contra tal escala (57\% dos oficiais e $53 \%$ dos praças), ainda que a jornada de 12 horas de serviço com as respectivas folgas seja, em seu somatório semanal, de 48 horas, ou seja, equivalente à escala de 24 horas de serviço por 72 horas de folga, conforme a grande maioria afirmou concordar em cumprir.

O gasto com combustível para ir ao quartel mais vezes na semana para cumprir a jornada de trabalho foi o principal fator alegado, seguido da possibilidade de cumprir uma maior folga corrida (72 horas de descanso corrido).

\subsection{IMPLANTAÇÃO DE CARGA HORÁRIA SEMANAL DE 44H SEMANAIS PARA TODOS OS POLICIAIS MILITARES DA UNIDADE}

Na proposição da limitação da caga horária, observou-se que ambos os círculos hierárquicos as opiniões são divididas (com 56\% dos oficiais e 53\% dos praças favoráveis à limitação). Muitos não acreditam que é possível limitar as horas trabalhadas, pois sempre haveria alguém favorecido. Outros opinaram para que a carga horária fosse limitada a 40 horas semanais. 
Por outro lado, nas respostas daqueles que exercem trabalho administrativo (que, na sua maioria, trabalha até 30 horas semanais, conforme o Gráfico n01), observa-se que $60 \%$ são contra a implementação de jornada de 44 horas semanais, enquanto dentre os que se encontram no serviço operacional, $62 \%$ são a favor.

\subsection{INTENÇÃO DO OFICIAL EM ATIVAR O BANCO DE HORAS}

Observou-se que a totalidade dos oficiais pesquisados é a favor da implantação do banco de horas, para compensar as pequenas dispensas do serviço nas atividades operacionais ou administrativas (pequenos atrasos, frequentar a faculdade, necessidades de cunho pessoal), de modo que o trabalho excedido fosse compensado, no futuro, pela dispensa da quantia de horas trabalhadas.

Entretanto não se constatou a mesma unanimidade, quando este item foi perguntado aos praças, pois os que não trabalham duas jornadas de expediente (no caso do serviço administrativo) ou não atingem 48 horas semanais (no caso do serviço de policiamento) foram contra tal implantação (59\% a favor e $41 \%$ contra). Entre os que exercem apenas serviços operacionais, $61 \%$ foram a favor da implantação do banco de horas.

\section{CONCLUSÃO}

O trabalhador comum tem garantido, pela Constituição Federal, 44 horas semanais para as atividades laborais. Entretanto, os militares estaduais, até o ano de 2009, careciam de normatização do desempenho de suas tarefas, ficando uma norma em aberto, análoga aos regulamentos do Exército Brasileiro.

Desde então, foi editada uma série de normas, visando limitar as horas trabalhadas pelos Policiais Militares, mas as jornadas de trabalho chegam a atingir até 48 horas semanais para os que exercem o serviço de policiamento. Entretanto, os que exercem serviços administrativos, exercem, no máximo, 30 horas semanais, deixando uma lacuna de 18 horas de atividades.

Conforme demonstrado na pesquisa, existe uma diversidade de horas trabalhadas pelos policiais militares, ainda que exista regulamentação a esse respeito dentro da instituição desde 2009. Isto sugere uma falta de efetividade na fiscalização das diferentes cargas horárias.

Com a aplicação do questionário, foi verificado que aqueles que se encontram nos níveis estratégico/tático/ operacional estariam dispostos a mudar o atual sistema existente de horas de trabalho na corporação e aplicar efetivamente o proposto por esse estudo. Do mesmo modo, aqueles que estão no nível de execução estariam dispostos a aceitar tais mudanças, pois numa instituição militarizada, a resistência à mudança poderia contribuir para a não efetividade e eficiência defendida no presente estudo.

Existe alto interesse, por parte dos gestores pesquisados (oficiais) e por parte dos seus auxiliares (subtenentes e sargentos) e executores (cabos e soldados), sendo encontrada resistência a tais mudanças principalmente por quem exerce função administrativa.

Essa resistência pode ser verificada na não aplicação das jornadas impostas pelo comando da instituição e pela alegada falta de conhecimento da jornada de 12 horas de serviço, por 24 horas de folga, ou de 12 horas de serviço por 48 horas de folga. 
De fato, ao se tentar aplicar uma flexibilização (e consequentemente otimização) da jornada de trabalho, em um órgão militar, há de se esperar resistência, principalmente daqueles que terão de aumentar suas horas trabalhadas.

Kotter e Schlesinger, ao apontar as razões da resistência à mudança, afirmam que haveria "o desejo de não perder algo considerado valioso, a incompreensão sobre as razões da mudança e suas implicações, a crença de que a mudança não faz sentido para a organização e a baixa tolerância à mudança" (KOTTER; SCHLEISINGER, 1979, apud LIMA; CARRIERI; PIMENTEL, 2007, grifo nosso).

Assim, caso fosse de interesse da corporação para implementar as mudanças sugeridas, essas devem ser precedidas de forte campanha, dentro da corporação, explanando que o banco de horas serviria para diminuir as diferenças na corporação. Assim também a limitação da jornada de trabalho a 44 horas semanais iria gerar uma diferença de 4 horas a mais, a ser revertida em descanso, no caso daqueles que exercem serviço de policiamento.

Naturalmente, a PMRN é uma instituição na qual a relação formal é muito forte e será necessário um trabalho de conscientização sobre a importância da implementação de tais medidas, ainda que a resistência seja de uma minoria. É papel da instituição fazer com que seus membros estejam conscientes dos demais papeis desempenhado pelos pares, fazendo com que seu desempenho diário seja otimizado.

Motta, quando disserta sobre a mudança organizacional, refere-se a "geralmente, um processo complexo, [...] tendo em vista uma nova forma de comportamento coletivo [...]. A mudança sempre envolve o indivíduo e seu meio, sendo que o grande desafio é o de controlar o processo de mudança" (MOTTA, 1997, apud LIMA; CARRIERI; PIMENTEL, p.91).

Campos e Pires afirmam que grande parte das organizações públicas ainda adotam a rigidez formal, na sua jornada de trabalho, e que "não há dúvida de que o Brasil se caracteriza por apresentar flexibilidade, em relação ao cumprimento de horários, que será maior ou menor, de acordo com a realidade de cada instituição e dentro de cada setor específico, nas mesmas organizações" (CAMPOS; PIRES, 2014, p.3).

Tal rigidez formal se mostra ainda mais clara, no âmbito da PMRN, pois além de ser uma instituição militar (e como tal, pública), possui mais de 180 anos, tendo tradições e valores que frequentemente se chocam com novos modelos de gestão.

Como proposta após o resultado da pesquisa, os excessos de horas podem ser revertidos em folgas programadas com os seus respectivos comandantes de pelotão, ou com quem for designado para manter tal controle, esperando que, como consequência, venha a otimizar o serviço policial.

Já no serviço administrativo, poder-se-iam aproveitar as horas não trabalhadas, no reforço de policiamento em áreas nas quais fosse demandada tal necessidade, sem se lançar mão do pagamento da jornada extra (denominada Diária Operacional), gerando como consequência, otimização do erário público.

Dessa forma, a limitação da jornada de trabalho e o estabelecimento um banco de horas, trariam equidade entre os serviços, maior eficiência no trabalho administrativo, além de proporcionar melhor controle das horas trabalhadas e permitir que o serviço operacional que, de maneira simplificada, totaliza 48 horas em uma semana, seja reduzido 4 horas por semana, igualando-se ao previsto na Constituição. 


\section{REFERÊNCIAS BIBLIOGRÁFICAS}

BLASS, Leila Maria da Silva. Jornada de trabalho: uma regulamentação em múltipla escolha. Revista Brasileira de Ciências Sociais, v. 13, n. 36, 1998.

BRASIL. Constituição da República Federativa do Brasil, Brasília, 1988.

Lei no 9.601, de 21 de janeiro de 1998. "Dispõe sobre o Contrato de Trabalho Por Prazo Determinado e Dá Outras Providências", Brasília.

Decreto-lei nº 5.452, de 1 de maio de 1943. "Aprova a Consolidação das Leis do Trabalho. Rio de Janeiro.

Medida Provisória n².164-41, de 24 de agosto de 2001. Altera A Consolidação das Leis do Trabalho - Clt, Para Dispor Sobre O Trabalho A Tempo Parcial, A Suspensão do Contrato de Trabalho e O Programa de Qualificação Profissional, Modifica As Leis nos 4.923, de 23 de Dezembro de 1965, 5.889, de 8 de Junho de 1973, 6.321, de 14 de Abril de 1976, 6.494, de 7 de Dezembro de 1977, 7.998, de 11 de Janeiro de 1990, 8.036, de 11 de Maio de 1990, e 9.601, de 21 de Janeiro de 1998, e Dá Outras Providências, Brasília.

Ministério Da Defesa. Portaria nº 816, de 19 de dezembro de 2003. Regulamento Interno e dos Serviços Gerais (R-1). Brasília.

CAMPOS, Suzana Magalhães; PIRES, Felipe de Carvalho. Flexibilização da jornada de trabalho como instrumento da gestão para resultados. Congresso De Gestão Pública, Brasília, 2014.

LIMA, Marcelo Simão; CARRIERI, Alexandre de Pádua; PIMENTEL, Thiago Duarte.Resistência à mudança gerada pela implementação de sistemas de gestão integrada (ERP): um estudo de caso. Revista Gestão e Planejamento, v. 8, n. 1, 2007, p.89-105.

MACHADO, Danielle Carusi. Flexibilidade do mercado de trabalho: a questão do tempo de trabalho (Texto para discussão n. 062), CEDE UFF, Niterói, 2012.

MATAS, Carles Ramió. Los problemas de la implantación de la nueva gestión pública en las administraciones públicas latinas: modelo de Estado y cultura institucional. Revista del CLAD Reforma y Democracia, v. 21, 2001, p. 184-185.

PANTALEÃO, Sérgio Ferreira. Banco De Horas - Aspectos Para Validade. Disponível em: <http://www. guiatrabalhista.com.br/tematicas/banco-horas.htm>.

PINA, José Augusto; STOTZ, Eduardo Navarro. Participação nos lucros ou resultados e banco de horas: intensidade do trabalho e desgaste operário. Revista Brasileira de Saúde Ocupacional, v. 36, n. 123, 2011. POLÍCIA MILITAR DO RIO GRANDE DO NORTE. Portaria n 204/09-GCG, de 8 de setembro de 2009, Natal, 2009. . Resolução Administrativa nº 002/2010-GCG. Institui Jornada de Trabalho no âmbito da Polícia Militar e Da Outras Providências, Natal, 2010.

Resolução Administrativa n 011/2013-GCG, de 2010. Estabelece O Horário do Expediente Administrativo na Polícia Militar do Rio Grande do Norte e Dá Outras Providências, Natal, 2010.

Resolução Administrativa nº 001/2013, de 2013. Institui Jornada de Trabalho e Estabelece Horários de Passagem de Serviço no âmbito da Polícia Militar e Dá Outras Providências, Natal, 2013. . Portaria No 107/2015-GCG, Natal, 2015. 
. Portaria No 113/2015-GCG, Natal, 2015.

RIO GRANDE DO NORTE. Lei n 4.630, de 16 de dezembro de 1976. Estatuto dos Policiais Militares do Estado do Rio Grande do Norte, Natal.

\section{Constituição Estadual, Natal, 1989.}

Decreto $n^{\circ}$ 21.614, de 07 de abril de 2010. Dispõe sobre A Criação do Comando de Policiamento Metropolitano - CPM e dos Comandos de Policiamento Regionais - CPR, na Estrutura Organizacional Básica da Polícia Militar, e dá Outras Providências, Natal.

SILVA, Débora Duarte da Silveira. A Gestão do trabalho e as relações sócio profissionais nas Organizações contemporâneas. Dissertação (Mestrado), Pontifica Universidade Católica-RJ, Rio de Janeiro, 2012.

VIANA, Rodrigo de Araújo. A eficiência como um dos princípios norteadores da Administração Pública, 2012. Disponível em: <http://www.conteudojuridico.com.br/artigo,a-eficiencia-como-um-dos-principiosnorteadores-da-administracao-publica,39867.html>. 


\section{APÊNDICE A - Questionário aplicado aos Oficiais}

1. Identificação
( ) Oficial
( ) Superior
( ) Intermediário
( ) Subalterno

2. Função Desempenhada

( ) Cmt OPM ( ) SCmt OPM ( ) EM/OPM （ ) Cmt Cia （ ) Cmt Pel

3. Função Desempenhada

( ) Operacional ( ) Administrativo

4. Na Opinião do Sr. a jornada de 44h semanais traria equidade entre os diversos tipos de atividades operacionais na vossa OPM?
( ) $\operatorname{sim}$
( ) Não

5. O Sr. tinha conhecimento que a atual jornada de trabalho da PMRN (12h por $24 \mathrm{~h}$ de descanso por 12h por 48h de descanso) existe desde 2013? (Resolução Administrativa No. 001/2013 - GCG que Institui Jornada de Trabalho e estabelece horários de passagem de serviço no âmbito da Polícia Militar.)
( ) Sim
( ) Não

6. Caso Negativo, o Sr(a) concorda em implantar o que traz seu Art. $1^{\circ}$ onde fica estabelecida no âmbito da Polícia Militar, a Jornada de Trabalho no serviço operacional motorizado nos turnos matutino e vespertino de 12 horas de serviço, por 24 horas de folga e no turno noturno de 12 horas de serviço por 48 horas de folga.
( ) Sim
( ) Não

7. O Sr.(a) é favorável para a implantação de carga horária semanal de 44h semanais para todos os policiais militares da sua unidade? Por quê?
( ) $\operatorname{sim}$
( ) Não

Porque?

8. O Sr. (a), como gestor, ativaria o banco de horas para as pequenas dispensas do serviço nas atividades operacionais ou administrativas (Faculdade, necessidades de cunho pessoal), bem como o trabalho excedido fosse compensado no futuro pela dispensa de certa quantia em horas trabalhadas?
( ) sim
( ) não

9. Caso queira, deixe um comentário acerca do assunto do presente questionário 


\section{APÊNDICE B - Questionário aplicado aos Praças}

1. Identificação
( ) ST/Sgt
( ) $\mathrm{Cb}$
( ) Sd

2. Função Desempenhada

( ) Operacional ( ) Administrativo

3. Carga Horária semana

( ) 20h - Meio Expediente diário

( ) $48 \mathrm{~h}$ - Escala $24 \mathrm{~h}$ de serviço por $72 \mathrm{~h}$ de folga

( ) Outro. Qual?

4. O Sr.(a) é favorável para a implantação de carga horária semanal de 44h semanais para todos os policiais militares da sua unidade? Por quê?
( ) $\operatorname{sim}$
( ) Não

Porque?

5. Na opinião do Sr. (a) a jornada de 44h horas semanais poderia trazer equidade entre os diversos tipos de atividades desempenhadas pelos policiais militares (Operacional/Administrativo)?
( ) Sim
( ) Não

6. O Sr. tinha conhecimento que a atual jornada de trabalho da PMRN (12h por 24h de descanso por $12 \mathrm{~h}$ por 48h de descanso) existe desde 2013? (Resolução Administrativa No. 001/2013 - GCG que Institui Jornada de Trabalho e estabelece horários de passagem de serviço no âmbito da Polícia Militar.)
( ) Sim
( ) Não

7. Caso Negativo, o Sr (a) concorda em cumprir o que traz seu Art. $1^{\circ}$ onde fica estabelecida, a Jornada de Trabalho no serviço operacional motorizado nos turnos matutino e vespertino de 12 horas de serviço, por 24 horas de folga e no turno noturno de 12 horas de serviço por 48 horas de folga.
( ) $\operatorname{Sim}$
( ) Não

Se não, comente

8. Como consequência da implementação da jornada de 44h horas semanais, é a favor do banco de horas em sua unidade?
( ) $\operatorname{sim}$
( ) Não

9. Caso queira, deixe um comentário acerca do assunto do presente questionário 
Jornada de trabalho na PMRN: o estabelecimento de limite e viabilidade de implantação de banco de horas nas unidades operacionais do Comando de Policiamento Metropolitano

Gustavo Henrique Lins Barreto
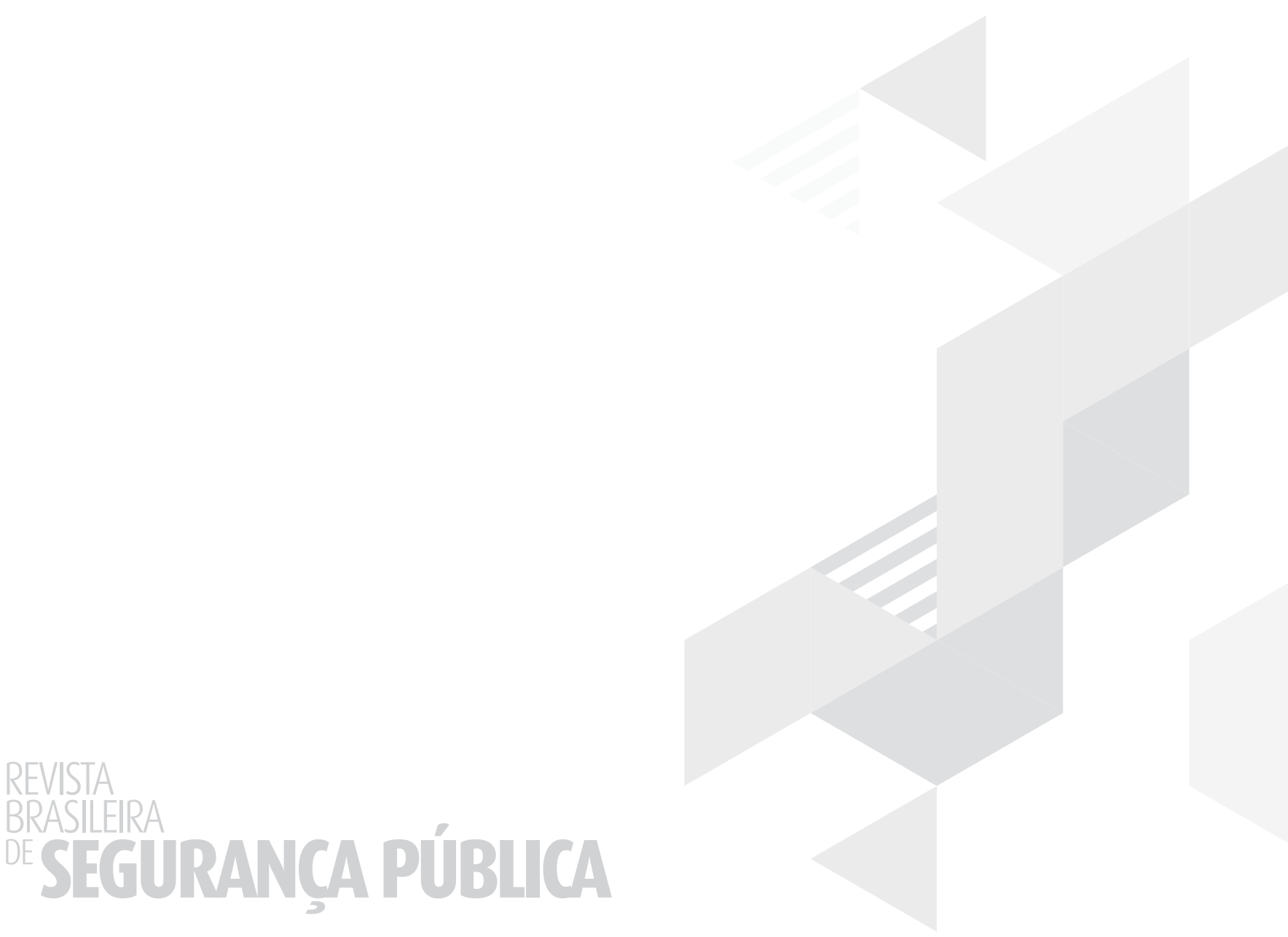